\title{
Use of Plasma Metabolite Concentrations after Glucose Injection to Predict the Genetic Ability of Milk Production in Young Calves
}

\author{
Osamu SASAKI ${ }^{1,2 *}$, Naoyuki YAMAMOTO ${ }^{2}$, Kenji TOGASHI $^{2}$, \\ Mituru MINEZAWA ${ }^{3}$, Kazuo ISHII ${ }^{4}$ and Hisato TAKEDA ${ }^{4}$ \\ 1,2 Department of Animal Production and Grassland, National Agricultural Research Center for \\ Hokkaido Region (Sapporo, Hokkaido 062-8555, Japan) \\ Genebank, National Institute of Agrobiological Sciences (Tsukuba, Ibaraki 305-8602, Japan) \\ 4 Department of Animal Breeding and Reproduction, National Institute of Livestock and \\ Grassland Science (Tsukuba, Ibaraki 305-0901, Japan)
}

\begin{abstract}
The objective of this study was to identify useful secondary traits to improve the prediction of the genetic ability of milk production in dairy cattle. Thirty-seven Holstein calves were injected with glucose at the rate of $0.15 \mathrm{~g} / \mathrm{kg}$ body weight after $24 \mathrm{~h}$ fast. A total of 566 milk records in 238 Holstein cows were collected. Plasma glucose concentration reached a peak $10 \mathrm{~min}$ after the injection. The concentrations of plasma non-esterified fatty acids (NEFA) and total ketone decreased 20 and 30 min after the injection, respectively. The collected blood samples were classified into 3 time groups: T1, 10 to $30 \mathrm{~min}$; T2, 40 to $60 \mathrm{~min}$; and T3, 70 to $90 \mathrm{~min}$ after the glucose injection. Heritability estimates of the plasma glucose, NEFA and total ketone concentrations ranged from 0.60 to 0.97 among the 3 time groups (T1, T2, and T3). Genetic correlation between the plasma glucose concentration and milk yield ranged from 0.50 to 0.76 in $\mathrm{T} 1, \mathrm{~T} 2$ and $\mathrm{T} 3$. Genetic correlation between plasma glucose concentration and fat yield in $\mathrm{T} 1$ and $\mathrm{T} 2$ was -0.43 and -0.35 , respectively. Genetic correlations between plasma NEFA or total ketone concentrations and milk production ranged from -0.22 to -0.97 . The use of the concentrations of plasma metabolites increased the reliability of breeding values for animals without milk records by 7.7 to $122.9 \%$, suggesting that the determination of the concentrations of plasma metabolites may improve the accuracy of prediction of the genetic ability of milk production traits. The combination of fast and glucose injection provides a suitable technique for generating plasma metabolites to predict the genetic merit of milk production in dairy cattle.
\end{abstract}

Discipline: Animal industry

Additional key words: dairy cattle, REML, reliability

\section{Introduction}

An accurate estimation of a cow's milk producing ability requires many records of her own ability and of that of her relatives. Genetic progress in milk production is slow because milk production traits are expressed only in the mature females ${ }^{19}$. It is also necessary to select replacement heifers in order to maintain a constant number of animals in a herd. Because the prediction of the genetic potential of replacement heifers is not accurate, their contribution to genetic improvement through selection is quite limited. If some traits were significantly correlated with milk production and could be easily measured in calves, selection to shorten the generation interval and accelerate the rate of genetic improvements might become easier ${ }^{18,20}$. Many authors suggested that milk production traits are associated with plasma metabolite concentrations in fast ${ }^{7,11,12,18-20,23}$. Maximum degree of physiological lipolysis was observed when the energy intake was restricted. The maximum response may be controlled genetically9. Sinnett-Smith et al. ${ }^{19}$ reported

\footnotetext{
Present address:

${ }^{1}$ Department of Animal Breeding and Reproduction, National Institute of Livestock and Grassland Science

(Tsukuba, Ibaraki 305-0901, Japan)

*Corresponding author: fax +81-29-838-8606; e-mail sasa1@affrc.go.jp

Received 30 October 2002; received 24 January 2003.
} 
that adipocytes with a high genetic merit may be more sensitive to lipolytic signals from the nervous or endocrine systems. Glucose and insulin are homeostatic regulators of the lipid metabolism in the adipose tissue ${ }^{2}$. Xing et al. ${ }^{24}$ reported that the insulin response to an exogenous glucose load could be used as a metabolic marker to predict the production performance. Fast tends to depress the amount of insulin released in response to the glucose load and results in a reduction of glucose tolerance ${ }^{3}$. Therefore, the combined use of fast and glucose injection could become a suitable technique for measuring the concentrations of metabolites to predict the genetic merit in dairy cattle.

The present study was conducted to estimate the heritability of the plasma metabolite concentrations and their genetic correlations with milk production in calves that received a glucose injection after $24 \mathrm{~h}$ fast and to investigate the suitability of the determination of the plasma metabolite concentrations for estimating the genetic ability of milk production.

\section{Materials and methods}

Two hundred and sixty nine Holstein cows fed at the National Agricultural Research Center for Hokkaido Region were used, of which 223 had milk production records only (G1), 31 had metabolite records only (G2), and 6 had both milk production and metabolite records (G3). Thirty-seven calves (20 females and 17 males) with metabolite records (G2 and G3) were born between 1995 and 1998. They were divided into 6 environmental groups (EG): 3 classes of birth month (February to April, May to June, July to August) in combination with 2 groups of feeding practices (pen in cowshed vs. calf hatch out of cowshed). The calves were randomly assigned to $6 \mathrm{EG}$. All the calves were fed twice a day at 9:00 and 16:00. The calves received $5.0 \mathrm{~kg}$ /day of whole milk and $0.6 \mathrm{~kg}$ /day of calf starter. Hay and water were provided ad libitum. This experiment was based on the guidelines for the care and use of agricultural animals in agricultural research.

The food was removed from all the calves at 9:00 at the age of $41 \pm 4$ days. Blood samples were collected into test tubes with heparin the following day at 9:00 by jugular vein puncture, followed by an injection of 50\% (w/v) glucose per $0.15 \mathrm{~g} / \mathrm{kg}$ body weight. Blood samples were collected at $10 \mathrm{~min}$ intervals for $90 \mathrm{~min}$ after the injection. Plasma was stored at $-20^{\circ} \mathrm{C}$ prior to analysis. The concentrations of glucose (Kainos Laboratories Inc., Japan), non-esterified fatty acids (NEFA) (Kainos Laboratories Inc., Japan), triglycerides (Kainos Laboratories Inc., Japan), and total ketone (Nittobo Medical Inc.,
Japan) were determined using a 7250 automatic analyzer (Hitachi Ltd., Japan) with commercially supplied reagent kits.

The GLM procedure of $\mathrm{SAS}^{14}$ was used to analyze the first-stage factor effects (EG and sex), second-stage factor effect (sampling time), and their interaction with the metabolite concentrations. The statistical model used to analyze the plasma metabolite concentrations was as follows:

$$
\begin{aligned}
\mathrm{Y} 1_{\mathrm{ijkm}}= & \mathrm{MH}_{\mathrm{j}}+\mathrm{S}_{\mathrm{k}}+\mathrm{e} 1_{\mathrm{jk}}+\mathrm{T}_{\mathrm{i}}+\mathrm{T}^{*} \mathrm{MH}_{\mathrm{ij}}+\mathrm{T}^{*} \mathrm{~S}_{\mathrm{ik}} \\
& +\mathrm{e} 2_{\mathrm{ijkm}}
\end{aligned}
$$

where:

$$
\begin{aligned}
\mathrm{Y}_{\mathrm{ijkm}}= & \text { plasma metabolite concentrations of the } \\
& \mathrm{m}^{\text {th }} \text { animal in the } \mathrm{ij} \mathrm{k}^{\text {th }} \text { subclass, } \\
\mathrm{MH}_{\mathrm{j}}= & \text { effect of } \mathrm{j}^{\text {th }} \mathrm{EG}(\mathrm{j}=1 \text { to } 6), \\
\mathrm{S}_{\mathrm{k}}= & \text { effect of } \mathrm{k}^{\text {th }} \text { sex }(1=\text { female, } 2=\text { male }), \\
\mathrm{e}_{\mathrm{jk}}= & \text { residual effect of first-stage factor, } \\
\mathrm{T}_{\mathrm{i}}= & \text { effect of } \mathrm{i}^{\text {th }} \text { collection time }(0,10,20, \\
& 30,40,50,60,70,80,90 \text { min }), \\
\mathrm{T}^{*} \mathrm{MH}_{\mathrm{ij}}= & \text { interaction between collection time and } \\
& \text { EG, } \\
\mathrm{T}^{*} \mathrm{~S}_{\mathrm{ik}}= & \text { interaction between collection time and } \\
& \text { sex, } \\
\mathrm{e} 2_{\mathrm{ijkm}}= & \text { residual effect of second-stage factor. }
\end{aligned}
$$

A total of 566 records on milk, fat and protein yields for 240 to 305 days in 238 head (G1 and G2) were collected from January 1, 1983 to March 31, 1999. Short records of milk production were extended to a 305-day basis by the method of Wood ${ }^{22}$. The method of Sasaki et al. (1999) ${ }^{15}$ was used to correct milk yield records for the age effect at the time of delivery. The means of milk, fat and protein yields after adjustment for the effect of delivery age were $8,101 \pm 1,565,282.7 \pm 67.3$ and $232.8 \pm$ $52.6 \mathrm{~kg}$, respectively.

The plasma samples collected were classified into 3 groups according to the time of collection after injection: 10 to $30 \mathrm{~min}$ (T1), 40 to $60 \mathrm{~min}$ (T2), and 70 to $90 \mathrm{~min}$ (T3). Genetic parameters were estimated within each time group. The statistical model for the estimation of the genetic parameters included the effect of EG and the time after injection within each time group. The statistical model for the estimation of the genetic parameters for the plasma glucose, NEFA and total ketone concentrations was, where:

$$
\mathrm{Y} 1_{\mathrm{ijk}}=\mathrm{T}_{\mathrm{i}}+\mathrm{MH}_{\mathrm{j}}+\mathrm{u} 1_{\mathrm{k}}+\mathrm{e}_{\mathrm{ijk}}
$$

$$
\begin{aligned}
\mathrm{Y}_{\mathrm{ijk}}= & \text { plasma metabolite concentrations in the } \\
& \mathrm{k}^{\text {th }} \text { animal in the } \mathrm{ij}^{\text {th }} \text { subclass, } \\
\mathrm{T}_{\mathrm{i}}= & \text { fixed effect of the } \mathrm{i}^{\text {th }} \text { time in each time } \\
& \text { group, } \\
\mathrm{MH}_{\mathrm{j}}= & \text { fixed effect of } \mathrm{j}^{\text {th }} \mathrm{EG}, \\
\mathrm{u} 1_{\mathrm{k}}= & \text { total merit of additive genetic and group }
\end{aligned}
$$


Table 1. Genetic and residual variances, and heritability and standard error of milk production traits and plasma metabolite concentrations in each time group ${ }^{\text {a) }}$

\begin{tabular}{lrrr}
\hline \hline Time group & \multicolumn{1}{c}{$\begin{array}{c}\text { Genetic } \\
\text { variance }\end{array}$} & $\begin{array}{c}\text { Residual } \\
\text { variance }\end{array}$ & Heritability \\
\hline T1 & 150.288 & 101.926 & $0.60 \pm 0.08$ \\
Glucose & $128,305.352$ & $27,011.054$ & $0.83 \pm 0.04$ \\
NEFA ${ }^{\text {b) }}$ & $26,320.757$ & $1,951.238$ & $0.93 \pm 0.02$ \\
Total ketone & & & \\
T2 & 298.686 & 92.813 & $0.76 \pm 0.05$ \\
Glucose & $49,700.384$ & $14,914.976$ & $0.77 \pm 0.05$ \\
NEFA & $29,626.753$ & 855.906 & $0.97 \pm 0.01$ \\
Total ketone & 182.428 & & \\
T3 & $53,866.219$ & $19,003.568$ & $0.74 \pm 0.05$ \\
Glucose & $22,025.037$ & $2,032.753$ & $0.92 \pm 0.02$ \\
NEFA & & & \\
Total ketone & 860.648 & 864.952 & $0.50 \pm 0.04$ \\
Milk production traits & 327.621 & 544.859 & $0.38 \pm 0.04$ \\
Milk yield & $526,706.939$ & $632,734.174$ & $0.45 \pm 0.04$ \\
Fat yield & Protein yield & &
\end{tabular}

a): The blood samples were obtained 10 to $30 \mathrm{~min}$ after injection (T1), 40 to 60 min after injection (T2), and 70 to 90 min after injection (T3).

b): Non-esterified fatty acids.

effects on $\mathrm{k}^{\text {th }}$ animal,

$\mathrm{e}_{\mathrm{ijk}} \quad=$ residual effect.

The method of estimation of the genetic parameters for milk, fat and protein yields was described in the previous paper ${ }^{16}$. These parameters are shown in Table 1. The model was as follows:

where:

$$
\mathrm{Y} 2_{\mathrm{ijk}}=\mathrm{YP}_{\mathrm{i}}+\mathrm{M}_{\mathrm{j}}+\mathrm{u} 2_{\mathrm{k}}+\mathrm{e}_{\mathrm{ijk}}
$$

$\mathrm{Y} 2_{\mathrm{ijk}}=$ milk production trait in the $\mathrm{k}^{\text {th }}$ animal in the $\mathrm{ij}^{\text {th }}$ subclass,

$\mathrm{YP}_{\mathrm{i}} \quad=$ fixed effect of $\mathrm{i}^{\mathrm{th}}$ year-parity group. The delivery years were grouped every 3 years. The year groups were divided into 3 parity subclasses (first, second and after second lactation). The records in 1998 were allocated to the groups from 1995 to 1997.

$\mathrm{M}_{\mathrm{j}} \quad=$ fixed effect of $\mathrm{j}^{\text {th }}$ calving month,

$\mathrm{u} 2_{\mathrm{k}}=$ total merit of additive genetic and group effects on $\mathrm{k}^{\text {th }}$ animal,

$\mathrm{e}_{\mathrm{ijk}} \quad=$ random residual effect.
The relationship of the animals was traced back 3 generations from the cows with milk records and included the progenies of these cows. The relationship matrix consisted of a total of 699 animals (543 females, 156 males). All the animals with plasma metabolite measurements were included in the relationship matrix. Unknown sires were assigned to 3 genetic groups in relation to the birth year of their offspring (prior to 1960, 1960 to 1969 , and after 1969) as described in the report of Sasaki et al. ${ }^{15}$. Similarly, unknown dams were assigned to 8 genetic groups in relation to the birth year of their offspring (prior to 1960,1960 to 1964,1965 to 1969,1970 to 1974,1975 to 1979,1980 to 1984,1985 to 1989, and after 1989).

Restricted maximum likelihood for multiple trait animal model was used to estimate the heritability and genetic correlation based on the VCE4.2 program $^{6}$. Because of the difficulty in reaching a convergence in the multiple trait model, the genetic and residual variances were estimated using a single trait model. Genetic and residual covariances were estimated using the two-trait model.

The two-trait mixed model equation was as follows: 


$$
\left[\begin{array}{ccc}
\mathbf{X}^{\prime} \mathbf{R}^{-1} \mathbf{X} & 0 & \mathbf{X}^{\prime} \mathbf{R}^{-1} \mathbf{Z} \\
0 & \mathbf{G}_{0} \otimes \mathbf{A}_{\mathbf{g}}{ }^{\prime} \mathbf{A}^{-1} \mathbf{A}_{\mathbf{g}} & \mathbf{G}_{0} \otimes\left(-\mathbf{A}_{\mathbf{g}} \mathbf{A}^{-1}\right) \\
\mathbf{Z}^{\prime} \mathbf{R}^{-1} \mathbf{X} & \mathbf{G}_{0} \otimes\left(-\mathbf{A}^{-1} \mathbf{A}_{\mathbf{g}}\right) & \mathbf{Z}^{\prime} \mathbf{R}^{-1} \mathbf{Z}+\mathbf{G}_{0} \otimes \mathbf{A}^{-1}
\end{array}\right]\left[\begin{array}{c}
\hat{\mathbf{b}} \\
\hat{\mathbf{g}} \\
\hat{\mathbf{u}}
\end{array}\right]
$$

$$
=\left[\begin{array}{c}
\mathbf{X}^{\prime} \mathbf{R}^{-1} \mathbf{y} \\
0 \\
\mathbf{Z}^{\prime} \mathbf{R}^{-1} \mathbf{y}
\end{array}\right]
$$

with

$$
\mathrm{E}\left[\begin{array}{l}
\mathbf{u} \\
\mathbf{e}
\end{array}\right]=0, \mathrm{~V}\left[\begin{array}{l}
\mathbf{u} \\
\mathbf{e}
\end{array}\right]=\left[\begin{array}{ll}
\mathbf{G} & 0 \\
0 & \mathbf{R}
\end{array}\right]
$$

where:

y $=\mathrm{N} \times 1$ vector of observations $(\mathrm{N}=\mathrm{N} 1+\mathrm{N} 2$ as defined below),

b $\quad=p \times 1$ vector of fixed effect of EG in metabolites, and year-parity groups and calving month in milk production traits ( $p=$ total number of fixed effects of the first and second traits),

$\hat{\mathbf{g}}=\mathrm{n} \times 1$ vector of fixed effect of genetic group $(\mathrm{n}=$ number of genetic group effects),

$\hat{\mathbf{u}}=(\mathrm{q} \times 2) \times 1$ vector of the total merit of additive genetic $(\hat{a})$ and group effects $\left(\hat{\mathbf{u}}=\hat{\mathbf{a}}+\mathbf{A}_{\mathbf{g}} \hat{\mathbf{g}}\right) \quad(\mathrm{q}=$ number of animals),

e $\quad=\mathrm{N} \times 1$ vector of random residuals,

$\mathbf{X}=\mathrm{N} \times \mathrm{p}$ incidence matrix for fixed effects,

$\mathbf{Z}=\mathrm{N} \times(\mathrm{q} \times 2)$ incidence matrix for random effects,

A $=\mathrm{q} \times \mathrm{q}$ matrix of additive relationships,

$\mathbf{A}_{\mathbf{g}}=\mathrm{q} \times \mathrm{n}$ matrix of additive relationships between animals and groups,

$\mathbf{G}=\mathbf{G}_{0} \otimes \mathbf{A}$ with $\otimes$ being the direct product operator,

$\mathbf{G}_{\mathbf{0}} \quad=$ genetic covariance matrix,

$\mathbf{R}=\left[\begin{array}{ll}\mathbf{R}_{11} & \mathbf{R}_{12} \\ \mathbf{R}^{\prime}{ }_{12} & \mathbf{R}_{22}\end{array}\right]$ where $\mathbf{R}_{11}=\mathrm{N} 1 \times \mathrm{N} 1$

residual covariance matrix of first trait (N1 = number of records for first trait), $\mathbf{R}_{22}=\mathrm{N} 2 \times \mathrm{N} 2$ residual covariance matrix of second trait $(\mathrm{N} 2=$ number of records for the second trait), and $\mathbf{R}_{\mathbf{1 2}}=\mathrm{N} 1 \times \mathrm{N} 2$ residual covariance matrix between first and second traits.

The reliability of the breeding value for the milk production trait was estimated by the method of Da et al. $(1989)^{4}$. The first genetic group effect was restricted to zero in the estimation of the reliability.

where:

$$
\gamma_{i}=\sqrt{1-\left(d_{i} / \sigma_{a}^{2}\right)}
$$

$$
\begin{aligned}
\gamma_{i}= & \text { reliability of } \mathrm{i}^{\text {th }} \text { rank, } \\
\mathrm{d}_{\mathrm{i}}= & \text { diagonal element of } \mathrm{i}^{\text {th }} \text { rank of } \\
& \left(\mathbf{M}_{\mathrm{x}}+\mathrm{M}_{\mathrm{a}}\right)^{-1}, \\
\sigma_{\mathrm{a}}^{2}= & \text { additive genetic variance of milk pro- } \\
& \text { duction traits, } \\
\mathbf{M}_{\mathbf{x}}= & \mathbf{Z}^{\prime} \mathbf{R}^{-1} \mathbf{Z}-\mathbf{Z}^{\prime} \mathbf{R}^{-1} \mathbf{X}\left(\mathbf{X}^{\prime} \mathbf{R}^{-1} \mathbf{X}\right)^{-1} \mathbf{X}^{\prime} \mathbf{R}^{-1} \mathbf{Z}, \\
\mathbf{M}_{\mathbf{a}}= & \mathbf{G}^{-1} \otimes\left(\mathbf{A}^{-1}-\mathbf{T}_{\mathrm{gu}}^{\prime} \mathbf{T}_{\mathrm{gg}}^{-1} \mathbf{T}_{\mathrm{gu}},\right. \\
\mathbf{T}_{\mathrm{gu}}= & -\mathbf{A}_{\mathbf{g}}^{\prime} \mathbf{A}^{-1}, \\
\mathbf{T}_{\mathrm{gg}}= & \mathbf{A}_{\mathrm{g}}^{\prime} \mathbf{A}^{-1} \mathbf{A}_{\mathrm{g}} .
\end{aligned}
$$

The reliabilities of milk production were estimated in 2 different ways as follows: (1) using milk records only (E1), and (2) using both milk and metabolite records (E2). The reliabilities of the milk production traits of the animals in $\mathrm{G} 2$ were chosen based on the results of E1 and $\mathrm{E} 2$, respectively. The mean reliability of E1 (E1G2) was compared with that of E2 (E2G2). Similarly, the reliabilities of the animals in G3 were chosen based on the results of E1 and E2, respectively. The mean reliability of E1 (E1G3) was compared with that of E2 (E2G3).

The GLM procedure of SAS $(1993)^{14}$ was used to estimate the least square means of metabolite concentrations and the reliability of the milk production traits. The difference in the reliabilities between E1 and E2 was tested using the Dunnett's multiple comparison method ${ }^{5}$.

\section{Results}

The least square means of the plasma metabolite concentrations after glucose injection are shown in Fig. 1. Sampling time exerted significant effects $(p<0.01)$ on the plasma glucose, NEFA, and total ketone concentrations. The plasma glucose level reached a peak at $10 \mathrm{~min}$ after the injection and then decreased from 10 to $90 \mathrm{~min}$ after the injection. The plasma NEFA level decreased from 0 to $20 \mathrm{~min}$ after the injection and then increased from 20 to $40 \mathrm{~min}$ and from 80 to $90 \mathrm{~min}$ after the injection. The plasma total ketone level showed a similar pattern of changes to that of NEFA. The plasma total ketone level decreased from 0 to $30 \mathrm{~min}$ after the injection and then increased from 30 to $40 \mathrm{~min}$ and from 80 to $90 \mathrm{~min}$ after the injection. The plasma triglyceride level changed with time like NEFA, although the triglyceride level was less affected by the sampling time. EG exerted significant effects on the total ketone level $(\mathrm{p}<0.05)$. Sex and interaction of the collection time with sex or with EG did not exert significant effects on the concentrations of any of the metabolites.

Genetic and residual variances and heritability esti- 


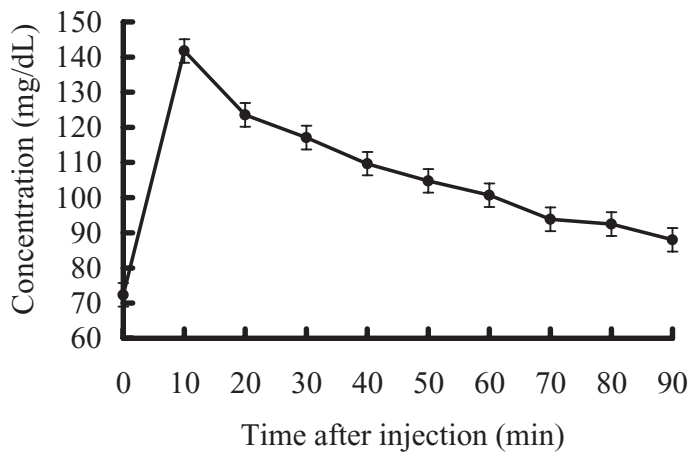

(a) Glucose

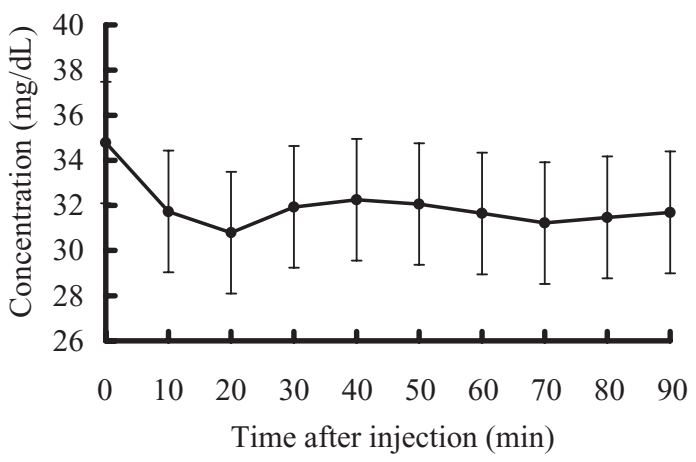

(c) Triglycerides

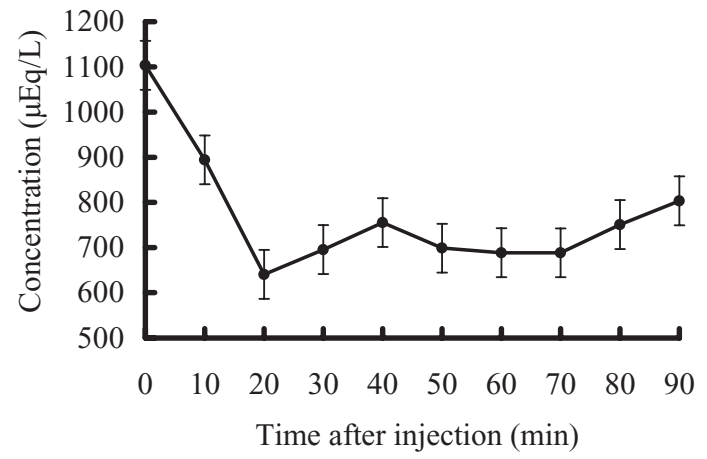

(b) NEFA

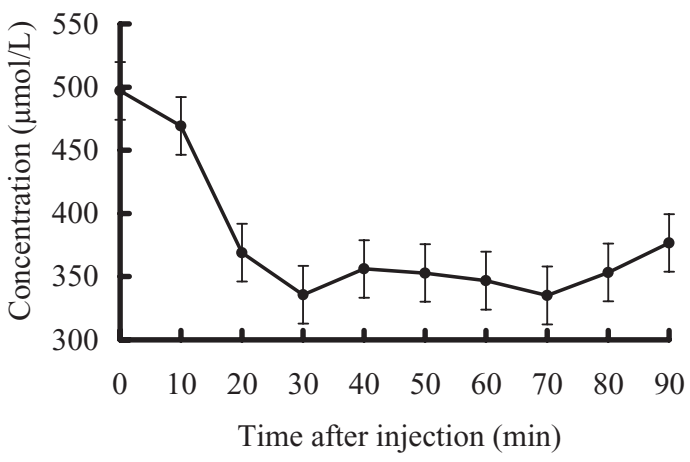

(d) Total ketone

Fig. 1. Least square means of plasma concentrations of (a) glucose, (b) non-esterified fatty acids (NEFA), (c) triglycerides and (d) total ketone in calves after glucose injection. Vertical bars denote the standard error on each sampling day.

mates of the plasma glucose, NEFA and total ketone concentrations are shown in Table 1. Heritabilities for all the metabolite concentrations were high in the 3 time groups. Genetic correlations between the plasma metabolite concentrations are shown in Table 2. Genetic correlations between the NEFA and total ketone concentrations were high and positive in all the time groups.

Genetic correlations between the plasma metabolite concentrations and milk production traits are shown in Table 3. Milk yield displayed a highly positive genetic correlation with the plasma glucose concentrations, but a highly negative genetic correlation with the plasma NEFA and total ketone concentrations in all the time groups. Fat yield exhibited a highly negative genetic correlation with the plasma NEFA concentration in T1 and T2. Because the genetic correlation between the fat yield and plasma NEFA concentration in T3 failed to converge, the analysis of the reliability of fat yield was not performed in T3. Fat yield showed a highly negative genetic correlation with the plasma total ketone concentration of T3. Protein yield showed a highly negative genetic correlation with the plasma NEFA and total ketone concentrations in all the time groups.
The least square means of the reliability of milk, fat and protein yields in E1G2 and their standard errors were $0.38 \pm 0.01,0.39 \pm 0.01$ and $0.35 \pm 0.01$, respectively. The least square means of the reliability of milk, fat and

Table 2. Genetic correlation and standard error between 2 plasma metabolite concentrations in each time $\operatorname{group}^{a}$

\begin{tabular}{lcr}
\hline \hline Time group & NEFA $^{\text {b) }}$ & Total ketone \\
\hline T1 & & \\
Glucose & $0.36 \pm 0.17$ & $-0.23 \pm 0.16$ \\
NEFA & & $0.51 \pm 0.12$ \\
T2 & & \\
Glucose & $-0.08 \pm 0.17$ & $-0.12 \pm 0.15$ \\
NEFA & & $0.75 \pm 0.08$ \\
T3 & & \\
Glucose & $0.28 \pm 0.17$ & $0.17 \pm 0.16$ \\
NEFA & & $0.62 \pm 0.10$ \\
\hline
\end{tabular}

a): The blood samples were obtained 10 to $30 \mathrm{~min}$ after injection (T1), 40 to $60 \mathrm{~min}$ after injection (T2), and 70 to 90 min after injection (T3).

b): Non-esterified fatty acids. 
Table 3. Genetic correlation between plasma metabolite concentrations and milk production traits in each time group ${ }^{\text {a) }}$

\begin{tabular}{lrrr}
\hline \hline Time group & Milk yield & Fat yield & Protein yield \\
\hline T1 & & & \\
Glucose & $0.76 \pm 0.47$ & $-0.43 \pm 0.48$ & $-0.04 \pm 0.46$ \\
NEFA ${ }^{\text {b) }}$ & $-0.53 \pm 0.38$ & $-0.85 \pm 0.30$ & $-0.97 \pm 0.32$ \\
Total ketone & $-0.47 \pm 0.37$ & $-0.34 \pm 0.47$ & $-0.50 \pm 0.46$ \\
T2 & & \\
Glucose & $0.67 \pm 0.48$ & $-0.35 \pm 0.45$ & $0.04 \pm 0.42$ \\
NEFA & $-0.82 \pm 0.40$ & $-0.83 \pm 0.40$ & $-0.42 \pm 0.45$ \\
Total ketone & $-0.65 \pm 0.35$ & $-0.22 \pm 0.54$ & $-0.44 \pm 0.47$ \\
T3 & & & \\
Glucose & $0.50 \pm 0.46$ & $-0.19 \pm 0.43$ & $0.22 \pm 0.45$ \\
NEFA & $-0.92 \pm 0.40$ & NC & $-0.52 \pm 0.58$ \\
Total ketone & $-0.81 \pm 0.42$ & $-0.83 \pm 0.56$ & $-0.66 \pm 0.59$ \\
\hline a): The blood samples were obtained 10 to 30 min after injection (T1), \\
40 to 60 min after injection (T2), and 70 to 90 min after injection (T3). \\
b): Non-esterified fatty acids. \\
c): No convergence.
\end{tabular}

Table 4. Least square means of reliabilities of milk production traits in each time group ${ }^{\text {a) }}$

\begin{tabular}{|c|c|c|c|c|c|c|}
\hline \multirow[t]{2}{*}{ Time group } & \multicolumn{3}{|c|}{ E2G2 } & \multicolumn{3}{|c|}{ E2G3 } \\
\hline & Milk yield & Fat yield & Protein yield & Milk yield & Fat yield & Protein yield \\
\hline \multicolumn{7}{|l|}{$\mathrm{T} 1$} \\
\hline Glucose & $0.61 * *$ & $0.47 * *$ & 0.35 & 0.73 & 0.72 & 0.62 \\
\hline $\mathrm{NEFA}^{\mathrm{b})}$ & $0.52 * *$ & $0.72 * *$ & $0.78 * *$ & 0.71 & $0.78 * *$ & $0.78^{* *}$ \\
\hline Total ketone & $0.49 * *$ & $0.46^{* *}$ & $0.49 * *$ & 0.70 & 0.72 & 0.66 \\
\hline \multicolumn{7}{|l|}{$\mathrm{T} 2$} \\
\hline Glucose & $0.59 * *$ & $0.45^{* *}$ & 0.35 & 0.73 & 0.71 & 0.62 \\
\hline NEFA & $0.67 * *$ & $0.69 * *$ & $0.45 * *$ & $0.75^{* *}$ & $0.78 * *$ & 0.65 \\
\hline Total ketone & $0.59 * *$ & $0.42 *$ & $0.46^{* *}$ & 0.73 & 0.71 & 0.65 \\
\hline \multicolumn{7}{|l|}{$\mathrm{T} 3$} \\
\hline Glucose & $0.50 * *$ & 0.41 & 0.38 & 0.70 & 0.71 & 0.63 \\
\hline NEFA & $0.73 * *$ & $\mathrm{NE}^{\mathrm{c})}$ & $0.49 * *$ & $0.78 * *$ & $\mathrm{NE}$ & 0.66 \\
\hline Total ketone & $0.68 * *$ & $0.71 * *$ & $0.58 * *$ & $0.76^{* *}$ & $0.78 * *$ & $0.69^{*}$ \\
\hline
\end{tabular}

The mean reliability of E2G2 was compared with that of E1G2. The mean reliability of E2G3 was compared with that of E1G3 $(* \mathrm{p}<0.05 ; * * \mathrm{p}<0.01)$. The means of E1G2 and E1G3 are shown in the text.

a): The blood samples were obtained 10 to $30 \mathrm{~min}$ after injection (T1), 40 to $60 \mathrm{~min}$ after injection (T2), and 70 to 90 min after injection (T3).

b): Non-esterified fatty acids.

c): Not estimated.

protein yields in E1G3 and their standard errors were $0.68 \pm 0.02,0.71 \pm 0.01$ and $0.62 \pm 0.02$, respectively. The reliabilities of milk, fat and protein yields in E2G2 and E2G3 were compared in Table 4. The reliability of milk yield in E2G2 was 28.9 to $92.1 \%$ higher $(\mathrm{p}<0.01)$ than in E1G2 due to the use of plasma metabolite concentrations. The reliability of fat yield in E2G2 was 15.4 to
84.6\% higher $(\mathrm{p}<0.01)$ than in E1G2 because of the use of the plasma glucose concentration or plasma NEFA concentration in $\mathrm{T} 1$ or $\mathrm{T} 2$, or the use of the plasma total ketone concentration in $\mathrm{T} 1$ or $\mathrm{T} 3$. The reliability of fat yield in $\mathrm{E} 2 \mathrm{G} 2$ was $7.7 \%$ higher $(\mathrm{p}<0.05)$ than in $\mathrm{E} 1 \mathrm{G} 2$ due to the use of the plasma total ketone concentration in T2. The reliability of protein yield in E2G2 was 28.6 to 
$122.9 \%$ higher $(\mathrm{p}<0.01)$ than in $\mathrm{E} 1 \mathrm{G} 2$ in response to the use of the plasma NEFA concentration or plasma total ketone concentration in all the time groups. The reliability of milk yield in E2G3 was 10.3 to $14.7 \%$ higher $(\mathrm{p}<0.01)$ than in E1G3 due to the use of the plasma NEFA concentration in $\mathrm{T} 2$ or $\mathrm{T} 3$ or plasma total ketone in T3. The use of the plasma NEFA concentration in T1 or T2 resulted in a $9.9 \%$ higher reliability of fat yield in E2G3 compared to E1G3. The reliability of protein yield in $\mathrm{E} 2 \mathrm{G} 3$ was $25.8 \%$ higher $(\mathrm{p}<0.01)$ than in $\mathrm{E} 1 \mathrm{G} 3$ due to the use of the plasma NEFA concentration in T1 and was $11.3 \%$ higher $(\mathrm{p}<0.05)$ than that in E1G3 due to the use of the plasma total ketone concentration in $\mathrm{T} 3$.

\section{Discussion}

The plasma NEFA and total ketone concentrations increased during the fast period in this experiment and then decreased when glucose was injected to the animals after fast. This trend of decline was in agreement with the results from previous reports ${ }^{17,21}$. Glucose may decrease the release of NEFA by supplying $\alpha$-glycerol phosphate for NEFA reesterification ${ }^{25}$. Glucose inhibits the release of fatty acids from the bovine adipose tissue in vitro $^{10}$. One or $2 \mathrm{~h}$ after the injection of glucose after $48 \mathrm{~h}$ fast, the concentration of blood glucose increased $(\mathrm{P}<0.01)$ and the level of NEFA decreased $(\mathrm{P}<0.01)$, compared with the injection of saline in 3 lambs $^{21}$. Glucose and insulin are homeostatic regulators of the lipid metabolism in the adipose tissue ${ }^{2}$. Serum insulin increased tenfold within 15 min of glucose injection ${ }^{3}$. Because insulin depresses the hormone-sensitive lipase activity, the plasma NEFA concentration decreased after glucose injection. The genetic correlation between the plasma glucose and NEFA concentrations was moderate in T1 and T3 (Table 2). The plasma total ketone concentration displayed a high genetic correlation with the plasma NEFA concentration in T1, T2 and T3. $\beta$-hydroxybutyric acid is derived from the oxidation of long-chain fatty acids when the animal shows a negative energy balance ${ }^{1,13}$. Therefore, the plasma total ketone concentration may change with the plasma NEFA concentration.

Heritability estimates for the plasma glucose, NEFA and total ketone concentrations from 40 to 60 days of age were $0.58,0.26$ and 0.91 , respectively ${ }^{16}$. In this study, heritabilities for the plasma glucose, NEFA and total ketone concentrations were very high $(0.60-0.97)$ in all the time groups, suggesting that the plasma metabolite concentrations were highly heritable when the animals were subjected to fast or received a glucose injection.

The insulin responses to exogenous glucose in the animals from a high breeding index line were much stronger than those of the animals from a low breeding index line ${ }^{24}$. Mackenzie et al. ${ }^{7}$ reported that during the challenges of both glucose and insulin, the clearance of blood glucose was most rapid in the calves with a high breeding index than in those with a low breeding index. As a result, the calves with a high breeding index exhibited a lower plasma glucose concentration after glucose injection. This study indicated that glucose showed a highly negative genetic correlation with fat yield, which is in agreement with the results from previous studies ${ }^{7,23}$. The sensitivity of the peripheral tissues to insulin was higher in the calves with a high breeding index than in those with a low breeding index. Therefore, the insulin response to an exogenous glucose load can be used as a metabolic marker to measure the genetic merit of milk production ${ }^{24}$. Glucose showed a highly positive genetic correlation with milk yield. The genetic correlation between milk and fat yield was positive in this herd ${ }^{15}$. The genetic correlations among glucose, milk yield and fat yield were inconsistent and it was difficult to draw conclusions in this experiment.

Genetic selection for milk production increased the milk energy secretion without significantly changing the milk fat percentage or net energy intake. Thus, genetic selection, along with adequate energy intake, increased the milk energy output and decreased the body weight gain with minimal or without changes in the net energy balance $^{8}$. Increased milk fat secretion due to genetic selection was associated with an increase in lipolysis?. Many authors investigated the relationship between milk production and the plasma NEFA concentration in fast. The relationship was either positive ${ }^{18,20}$ or absent $^{7,11,12,19,23}$. This discrepancy could be due to the low heritability of plasma NEFA concentration ${ }^{16}$. The combination of fast and glucose injection could become a suitable method for observing genetic differences in the fat metabolism, as the heritability estimate of the plasma NEFA concentration was very high in this study.

The rate of annual genetic gain depends on the reliability, selection intensity and generation interval. The annual genetic gain is proportional to the reliability of selection, when the selection intensity and generation interval are fixed in a breeding program. For animals without milk records, the group with information on plasma metabolite concentrations (E2G2) showed a higher reliability of milk production traits than that without such information (E1G2). The effect of metabolite information on the reliability was large in all the time groups. The changes in the plasma NEFA and total ketone concentrations were negligible during 30 to 70 min after glucose injection. Therefore, this period should be suitable for measuring the metabolite concentrations 
to predict the genetic potential of milk production. Because the number of animals used in this study was relatively small, the standard errors of the estimated heritabilities and genetic correlations were relatively large. Further studies on a larger number of animals should be conducted in order to confirm the results of this study.

\section{Conclusions}

The results of this study showed that the plasma metabolite concentrations could be used to improve the accuracy of estimation of the genetic merit of milk production, particularly for animals without milk records (e.g., immature male or female calves). Plasma glucose, NEFA and total ketone concentrations measured 30 to 70 minutes after glucose injection with $24 \mathrm{~h}$ of fast are useful indicators of the milk producing ability in commercial dairy herds where about half of the individuals are usually selected as replacements without milk records. Because the metabolite concentrations can be measured anytime from the neonatal stage onwards, the use of metabolite markers may shorten the generation interval and thus accelerate the rate of genetic improvement. The combination of fast and glucose injection could become a suitable measurement technique for predicting the genetic merit of milk production in dairy cows.

\section{References}

1. Adler, J. H. et al. (1963) Free fatty acids (FFA) and the origin of ketone bodies in cows. Vet. Rec., 75, 304-307.

2. Bauman, D. E. \& Currie, W. B. (1980) Partitioning of nutrients during pregnancy and lactation: a review of mechanisms involving homeostasis and homeorhesis. $J$. Dairy Sci., 63, 1514-1529.

3. Boda, J. M. (1964) Effect of fast and hexose injection on serum insulin concentrations of sheep. Am. J. Physiol., 206, 419-424.

4. Da, Y., Grossman, M. \& Misztal, I. (1989) Prediction error variance and restricted maximum likelihood estimation for animal model with relationship grouping. $J$. Dairy Sci., 72, 2125-2135.

5. Dunnett, C. W. (1995) A multiple comparisons procedure for comparing several treatments with a control. $J$. Am. Stat. Assoc., 50, 1096-1121.

6. Groeneveld, E. \& Cortes, A. G. (1998) VCE4.0 a (co)variance component package for frequentists and baysians. Proc. 6th World Congr. Genet. Appl. Livest. Prod., 27, 455-456.

7. Mackenzie, D. D. S. et al. (1988) Plasma metabolite and hormone concentrations as predictors of dairy merit in young Friesian bulls: effect of metabolic challenges and fasting. Anim. Prod., 47, 1-10.

8. McNamara, J. P. \& Hillers, J. K. (1986) Regulation of bovine adipose tissue metabolism during lactation. 1 . Lipid synthesis in response to increased milk production and decreased energy intake. J. Dairy Sci., 69, 30323041.

9. McNamara, J. P. \& Hillers, J. K. (1986) Regulation of bovine adipose tissue metabolism during lactation. 2 . Lipolysis response to milk production and energy intake. J. Dairy Sci., 69, 3042-3050.

10. Metz, S. H. M. \& van den Bergh, S. G. (1977) Regulation of fat mobilization in adipose tissue of dairy cows in the period around parturition. Neth. J. Agric. Sci., 25, 198211.

11. Min, S. H. et al. (1993) Plasma metabolite and hormone concentrations in Friesian calves of low or high genetic merit: effects of sex and age. Anim. Prod., 56, 17-27.

12. Olbrich-Bludau, A. et al. (1993) Relationship between age, nutritional status and dairy merit with plasma profiles of growth hormone (GH) and free fatty acids (FFA) in bulls. J. Anim. Breed. Genet., 110, 171-181.

13. Palmquist, D. L. (1972) Palmitic acid as a source of endogenous acetate and $\beta$-hydroxybutyrate in fed and fasted ruminants. J. Nutr., 102, 1401-1406.

14. SAS (1993) SAS/STAT Software User's Guide Version 6, First Edition. SAS Institute Japan, Tokyo, Japan, 569666

15. Sasaki, O., Yamamoto, N. \& Togashi, K. (1999) Estimation of breeding value for milk production traits in a Holstein herd with incomplete relationships. Anim. Sci. J., 70, J97-J105 [In Japanese].

16. Sasaki, O. et al. (2002) Plasma metabolites concentrations in calves until 90 days of age for estimating genetic ability for milk production traits. Asian-Australasian $J$. Anim. Sci., 15, 1813-1821.

17. Sasaki, Y., Kumazaki, K. \& Ikeda, O. (1974) Relationship between plasma glucocorticoids and the maintenance of blood glucose level in the fasted animals. Jpn. J. Zootech. Sci., 45, 81-87.

18. Sejrsen, K., Larsen, F. \& Andersen, B. B. (1984) Use of plasma hormone and metabolite levels to predict breeding value of young bulls for butterfat production. Anim. Prod., 39, 335-344.

19. Sinnett-Smith, P. A., Slee, J. \& Woolliams, J. A. (1987) Biochemical and physiological responses to metabolic stimuli in Friesian calves of differing genetic merit for milk production. Anim. Prod., 44, 11-19.

20. Tilakaratne, N. et al. (1980) Physiological attributes as possible selection criteria for milk production. 1. Study of metabolites in Friesian calves of high or low genetic merit. Anim. Prod., 30, 327-340.

21. Trenkle, A. \& Kuhlemeier, K. V. (1966) Relationship of rumen volatile acids, blood glucose and plasma nonesterified fatty acids in sheep. J. Anim. Sci., 25, 1111-1115.

22. Wood, P. D. P. (1967) Algebraic model of the lactation curve in cattle. Nature, 216, 164-165.

23. Xing, G. Q. et al. (1988) Plasma metabolite and hormone concentrations in Friesian calves differing in genetic potential for milkfat production. NZ. J. Agric. Res., 31, 159-167.

24. Xing, G. Q. et al. (1993) Pancreatic insulin responses to exogenous glucose in Friesian heifers of low or high genetic merit for milk-fat yield. Anim. Prod., 56, 171178.

25. Yang, Y. T. \& Baldwin, R. L. (1973) Lipolysis in isolated cow adipose cells. J. Dairy Sci., 56, 366-374. 